\title{
Take-off velocity, force and power features manifestation in training exercises of athletes
}

\author{
Andrey Pyanzin ${ }^{1 *}$ and Nadezhda Pyanzina $^{2}$ \\ ${ }^{1}$ Chuvash State Pedagogical University named after I.Y. Yakovlev, 428000, Cheboksary, Russia \\ ${ }^{21}$ Chuvash State University n. a. I.N. Ulyanov, 428000, Cheboksary, Russia
}

\begin{abstract}
The purpose of the study is to identify take-off velocity, force and power features manifestation in training exercises of athletes. 11 training exercises were subjected to metrological assessment. Analysis of take-off indicators allows us to assess their level individually for each athlete in each exercise. It greatly facilitates the coach's task of individual exercises selection.
\end{abstract}

\section{Introduction}

In athletics sprints, jumps and throws, the competitive result is determined, along with high technical skill, by the level of speed and strength abilities. These abilities reflect the manifestation of movement speed and muscle strength in such a combination that is necessary to achieve the maximum values of power when the athlete's body interacts with the external support in the main phase of the exercise.

The means aimed at the development of speed-strength abilities includes throwing, jumping exercises and running with various nonmaximum weights and resistances, as well as overcoming the resistance of one's own body weight. At the same time, the more significant the external weight overcome by the athlete (for example, when lifting the barbell to the chest), the greater the role of the strength component, and with less weight (for example, when throwing a javelin) the importance of the speed component increases. The range of exercises is wide enough, therefore, there is a need to assess their training potential and to select from this range of exercises that are most similar to competitive exercise in terms of kinematic and dynamic parameters of body interaction with the support.

At present, the issues of kinematic and dynamic take-off characteristics in athletics jumps [1-7] and other sports [8], the impact of individual exercises on speed and strength abilities manifestation [9] are well studied. The characteristics of body interaction with the support can be used to select speed and strength exercises that are appropriate to a particular athlete's individual characteristics [10].

The contradiction lies in the need for a clear understanding by the coach of the exercises impact used in training, on the one hand, and the disparity of information about this in the scientific and methodological literature, on the other hand.

\footnotetext{
* Corresponding author: pianzin@mail.ru
} 
Research problem: take-off velocity, force and power features manifestation in training exercises of athletes.

Object of research: special physical training process of athletes representing speed and strength disciplines.

Subject of research: take-off velocity, strength and power characteristics in the exercises of athletes representing speed and strength disciplines.

The purpose of the study is to identify the take-off velocity, force and power features in training exercises of athletes representing speed and strength disciplines.

\section{Materials and Methods}

The study was conducted on the basis of the sport school No. 1 named after V. Egorova, Cheboksary, Russia.

The subjects were tested in February-March 2020. The number of subjects included 7 athletes ( 2 sprinters, 2 long jumpers and 3 high jumpers). They had qualifications from the 2nd category to the Master of Sports ( 1 person with the 2nd category, 4 Candidate Masters of Sports, 2 Masters of Sports). A total number of 11 training exercises were subjected to metrological assessment:

1.2 legs standing vertical jump without arm swing.

2.2 legs standing vertical jump with arm swing.

3.2 legs jump on $80 \mathrm{~cm}$ box.

4.2 legs jump on $105-113 \mathrm{~cm}$ box.

5.2 legs drop jump from 90 up to $50 \mathrm{~cm}$ box.

6.2 legs drop jump from 50 up to $90 \mathrm{~cm}$ box.

7.2 legs jumps over hurdles $76-100 \mathrm{~cm}$ :

a) $1^{\text {st }}$ take-off,

b) $2-3^{\text {rd }}$ take-off.

8. Takeoff leg jumps over hurdles $67-91 \mathrm{~cm}$ :

a) $1^{\text {st }}$ take-off,

b) $2-3^{\text {rd }}$ take-off.

9. Takeoff leg jump on 105-113 cm box from 3 steps run-up.

10. Takeoff leg fivefold jump from 6 steps run-up:

a) $1^{\text {st }}$ take-off,

b) $2-5^{\text {th }}$ take-off.

11. $30 \mathrm{~m}$ running.

The subjects performed 2 attempts in each exercise. The best results were registered. In total, 161 measurements were made.

The study used the following methods: analysis of scientific and methodological literature on the research topic, accelerometry, methods of mathematical statistics.

Accelerometry was performed to measure the body's general center of mass acceleration during test exercises. In 2011, the Italian company Sensorize manufactured and presented the FreeSense device for recording individual technique parameters of athletes' sports movements. It allows measuring acceleration and angular velocities along 3 coordinate axes, as well as GPS coordinates [11]. To carry out measurements in our study, we used the Physics Toolbox Accelerometer mobile application installed on a smartphone [12,13]. It is the next generation of FreeSense-like measurement technology that allows to register quantitative values of accelerations and gravity in three projections with intervals of up to milliseconds and export data in spreadsheet format. The measurement of accelerations was carried out using a smartphone. It was attached with an elastic bandage at the back in the lumbar region, at the level of the $3-4^{\text {th }}$ lumbar vertebrae (Fig. 1). It was recommended for fixing a similar FreeSense device [1]. 

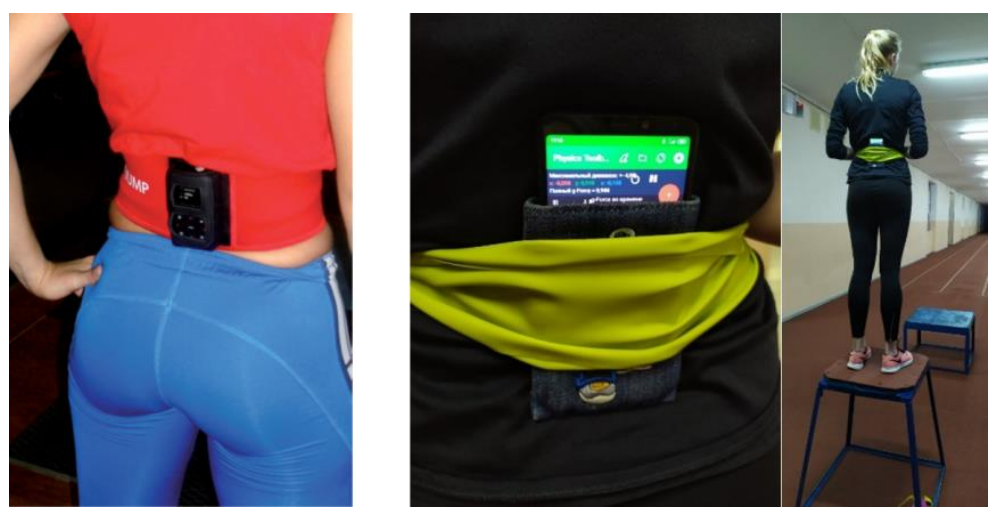

Fig. 1. Mounting the FreeSense measuring device (left) and the smartphone with the Physics Toolbox Accelerometer app. (right).

In jumping over hurdles on one and two legs, as well as in a 5-fold jump with 6 steps run-up, the first take-off is always performed in the absence or implicit manifestation of the shock absorption phase, while in subsequent take-offs this phase is pronounced. Therefore, when analyzing the quantitative data in these exercises, we considered it justified to consider the first take-off $(7 \mathrm{a}, 8 \mathrm{a}, 10 \mathrm{a})$ separately from the subsequent take-offs $(7 \mathrm{~b}, 8 \mathrm{~b}$, $10 b)$.

Methods of mathematical statistics were used for quantitative analysis of experimental data. Statistical processing of test results was carried out in the MS Excel software shell with calculation of sample mean values $(\mathrm{M})$ and standard deviations $(\sigma)$.

\section{Results and Discussion}

Since the parameters absolute values in exercises differed among different subjects, we determined the ratio of the absolute values in a particular training exercise to the absolute values in the basic exercise for each subject and for each measured characteristic. As a basic exercise, a kind of starting point for other exercises, a standing vertical jump without arm swing with a push of two legs was chosen. In this case, the take-off velocity, the average dynamic effort and the take-off force power in the basic exercise were equal to one. The individual coefficients obtained in this way made it possible to derive their average group values, both for individual parameters and as a whole (Table 1).

Table 1. Average group values of take-off velocity, force and power in test exercises, relative units.

\begin{tabular}{cccc}
\hline Exercise number & Take-off velocity, $\mathbf{M} \pm \boldsymbol{\sigma}$ & Take-off force, $\mathbf{M} \pm \boldsymbol{\sigma}$ & Take-off power, $\mathbf{M} \pm \boldsymbol{\sigma}$ \\
\hline 1 & $1,00 \pm 0,000$ & $1,00 \pm 0,000$ & $1,00 \pm 0,000$ \\
\hline 2 & $1,10 \pm 0,039$ & $1,25 \pm 0,166$ & $1,37 \pm 0,154$ \\
\hline 3 & $0,81 \pm 0,156$ & $1,65 \pm 0,212$ & $1,33 \pm 0,267$ \\
\hline 4 & $0,94 \pm 0,108$ & $1,66 \pm 0,265$ & $1,56 \pm 0,256$ \\
\hline 5 & $0,55 \pm 0,108$ & $2,57 \pm 0,303$ & $1,39 \pm 0,219$ \\
\hline 6 & $0,78 \pm 0,132$ & $2,49 \pm 0,317$ & $1,93 \pm 0,351$ \\
\hline $7 \mathrm{a}$ & $1,03 \pm 0,082$ & $2,13 \pm 0,516$ & $2,19 \pm 0,509$ \\
\hline $7 \mathrm{~b}$ & $1,03 \pm 0,038$ & $2,52 \pm 0,283$ & $2,59 \pm 0,217$ \\
\hline $8 \mathrm{a}$ & $0,90 \pm 0,103$ & $3,53 \pm 1,128$ & $3,14 \pm 0,979$ \\
\hline $8 \mathrm{~b}$ & $0,85 \pm 0,066$ & $3,97 \pm 0,714$ & $3,39 \pm 0,651$ \\
\hline 9 & $1,02 \pm 0,204$ & $3,20 \pm 0,875$ & $3,14 \pm 0,508$ \\
\hline $10 \mathrm{a}$ & $0,58 \pm 0,109$ & $2,64 \pm 0,754$ & $1,51 \pm 0,434$ \\
\hline
\end{tabular}




\begin{tabular}{cccc}
\hline $10 \mathrm{~b}$ & $0,58 \pm 0,117$ & $3,33 \pm 0,447$ & $1,96 \pm 0,588$ \\
\hline 11 & $0,29 \pm 0,044$ & $3,45 \pm 0,980$ & $0,97 \pm 0,191$ \\
\hline
\end{tabular}

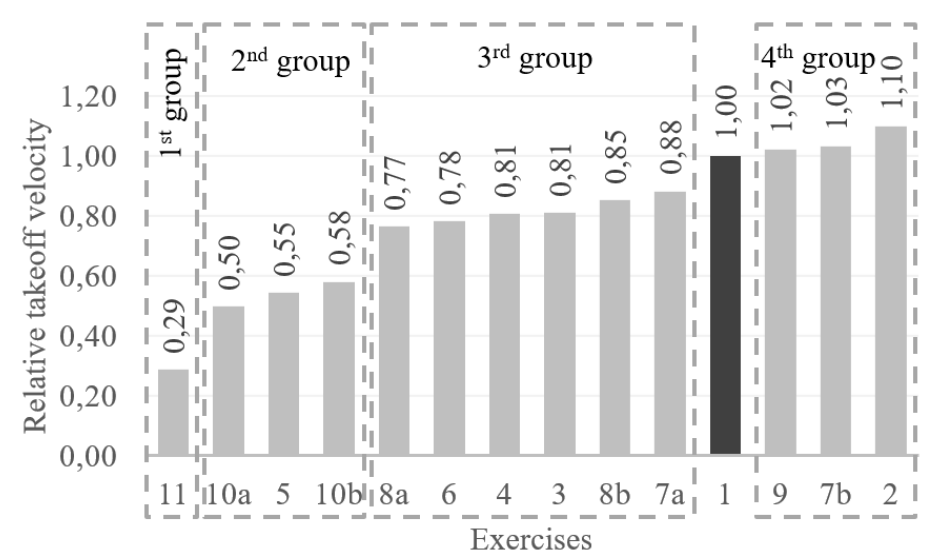

Fig. 2. Relative values of the take-off velocity vertical component in test exercises, relative units.

The vertical component of body take-off velocity was calculated based on the jump height values, determined taking into account the time between the moments of take-off and landing according to formulas known in physics. According to the manifestation level of body take-off velocity vertical component in the test exercises, there are 4 groups (Fig. 2 ). In the first group, the take-off velocity is one-third of the velocity in the basic exercise. The second group includes 3 exercises, the take-off velocity in which ranges from 50 to 60 $\%$ of the velocity in the basic exercise. The average take-off velocity in group 2 was 0.54 units. The third group includes 6 exercises, the take-off velocity in which ranges from 75 to $90 \%$ of the velocity in the basic exercise. The average take-off velocity in group 3 was 0.82 units. The fourth group includes 3 exercises, the take-off velocity in which exceeds the velocity in the basic exercise by no more than $10 \%$. The average take-off velocity in group 4 was 1.05 units.

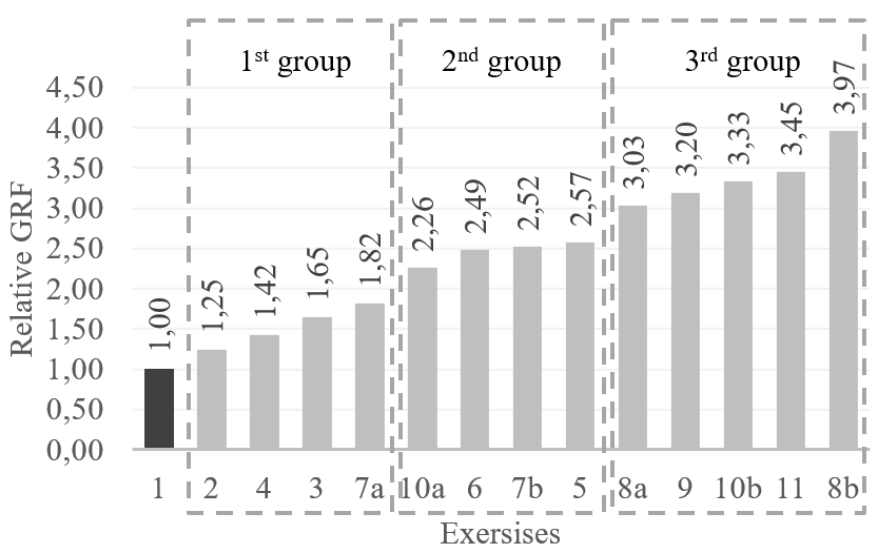

Fig. 3. Relative values of ground reaction force vertical component in the take-off phase (take-off force) for one leg in test exercises, relative units.

The acceleration vertical component recorded by the measuring device was converted into kilograms of force (kgf) by multiplying the instantaneous acceleration values by athlete's weight. According to the manifestation level of the ground reaction force vertical 
component average value in the test exercises, there are 3 groups (Fig. 3). The first group includes 4 exercises, the force values in which are within the range of 1 to 2 relative units. The average force value in these exercises is up to two times higher than in the basic exercise. The average value of the take-off force in group 1 was 1.54 units. The second group includes 4 exercises, the force values in which are within the range of 2 to 3 relative units, i.e. the average force value in these exercises is 2-3 times higher than in the basic exercise. The take-off force average value in group 2 was 2.46 units. The third group consists of 5 exercises, the force values in which exceed 3 relative units, i.e. the average force value in these exercises is more than 3 times higher than in the basic exercise. The take-off force average value in group 3 was 3.39 units.

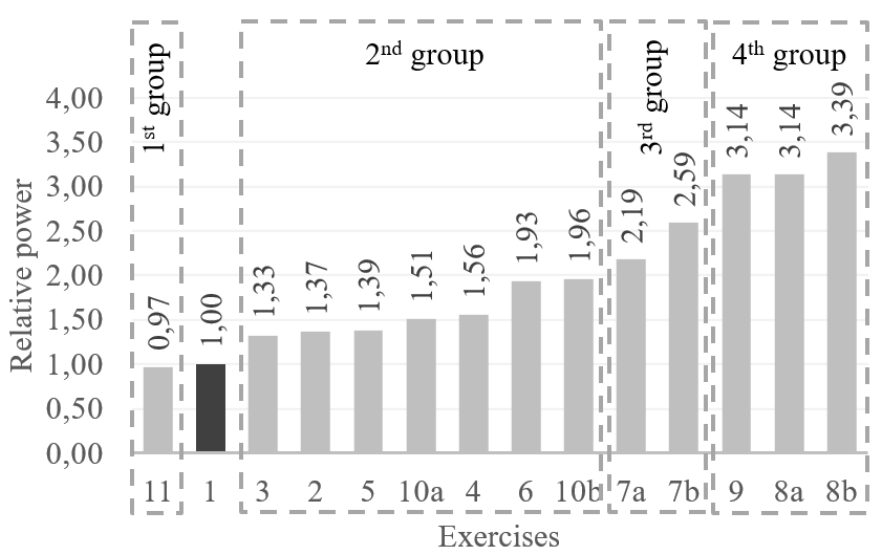

Fig. 4. The take-off power relative values in test exercises, relative units.

The take-off power was determined by multiplying of the vertical component value of body's take-off initial velocity by the ground reaction force vertical component. According to the manifestation level of take-off power in test exercises, there were 4 groups (Fig. 4). The only exercise that made up group 1 , the quantitative power value in which $(0.97)$ was lower than in the basic exercise (1.00), was sprint running. In groups 2-4 of exercises, the power values were higher than in the basic exercise. The second group consisted of 7 exercises, the power values in which were in the range from 1 to 2 relative units. The takeoff power average value in group 2 was 1.58 units. The third group contained 2 exercises, the power values in which were in the range from 2 to 3 relative units. The take-off power average value in group 3 was 2.39 units. The fourth group included 3 exercises, the power values in which exceeded 3 relative units. The take-off power average value in group 4 was 3.22 units.

\section{Conclusions}

Thus, the analysis allowed us to identify exercises with different manifestations of take-off velocity, force and power. Taking into account these parameters contributes to a more adequate training means choice in the implementation of various tasks in athletes' special physical training, individualization of its content.

The analysis of take-off velocity, force and power indicators allows us to assess their level individually for each athlete and in each exercise. It greatly facilitates the coach's task of individual exercises selection within the special physical training framework.

\section{References}


1. O. Aura, J.T. Viitasalo, J. Appl. Biom., 5-1, 89-98 (1989)

2. A. Lees, P. Graham-Smith, N. Fowler, J. Appl. Biom., 10, 61-78 (1994)

3. H. Hatze, J. Appl. Biom., 14, 127-140 (1998)

4. M.P. Greig, M.R. Yeadon, J. Appl. Biom., 16, 367-378 (2000)

5. C. Wilson, M.A. King, M.R. Yeadon, J. Biom., 44, 2207-2212 (2011)

6. I.M. Fletcher, Eur. J. Appl. Physiol., 109, 491-498 (2010)

7. M.S. Walsh, K.R. Ford, K.J. Bangen, G.D. Myer, T.E. Hewett, J. Strength Cond. Res., 20, 730-734 (2006)

8. M.T. Woolstenhulme, C.M. Griffiths, E.M. Woolstenhulme, A.C. Parcell, J. Strength Cond. Res., 20, 799-803 (2006)

9. M. Walsh, A. Arampatzis, F. Schade, G.-P. Brüggemann, Gert-Peter, J. Strength Cond. Res., 18, 561-566 (2004)

10. A.I. Pyanzin, N.N. Pyanzina, Proceedings, 26-30 (Churapcha, 2016)

11. Driver S. NSA, 26, 175-177 (2011)

12. Physics Toolbox Accelerometer https://www.vieyrasoftware.net/

13. A.I. Pyanzin, Pedagogico-psychological and medico-biological problems of physical culture and sports, 11(3), 118-125 (2016) 